\title{
Correction to: EphA2-YES1-ANXA2 pathway promotes gastric cancer progression and metastasis
}

Linfeng Mao (D), Weijie Yuan, Kaimei Cai, Chen Lai, Changhao Huang, Yi Xu, Shangwei Zhong, Chen Yang, Ran Wang, Pengwei Zeng, Heyuan Huang, Zhikang Chen and Zihua Chen (iD)

(c) The Author(s) 2021

Oncogene (2022) 41:1228-1230; https://doi.org/10.1038/s41388-021-02163-z

Correction to: Oncogene (2021) 40:3610-3623 https://doi.org/ 10.1038/s41388-021-01786-6, published online 3 May 2021

After publication of this article, we noticed errors in Fig. 5G in the original manuscript, in which the images of the ANXA2-KD Vector $(-)$ YES1(+) group were misused inadvertently. In this corrected version, we had replaced the incorrectly misused images with the correct original images and provided the correct Fig. 5 below. We confirm that the mistakes do not affect the results and conclusions of the study and apologize for any inconvenience caused by this mistake.

The corrected Fig. 5 is given below:

The original article has been corrected.

\begin{abstract}
(c) (i) Open Access This article is licensed under a Creative Commons BY Attribution 4.0 International License, which permits use, sharing, adaptation, distribution and reproduction in any medium or format, as long as you give appropriate credit to the original author(s) and the source, provide a link to the Creative Commons license, and indicate if changes were made. The images or other third party material in this article are included in the article's Creative Commons license, unless indicated otherwise in a credit line to the material. If material is not included in the article's Creative Commons license and your intended use is not permitted by statutory regulation or exceeds the permitted use, you will need to obtain permission directly from the copyright holder. To view a copy of this license, visit http://creativecommons. org/licenses/by/4.0/.
\end{abstract}

(c) The Author(s) 2021 

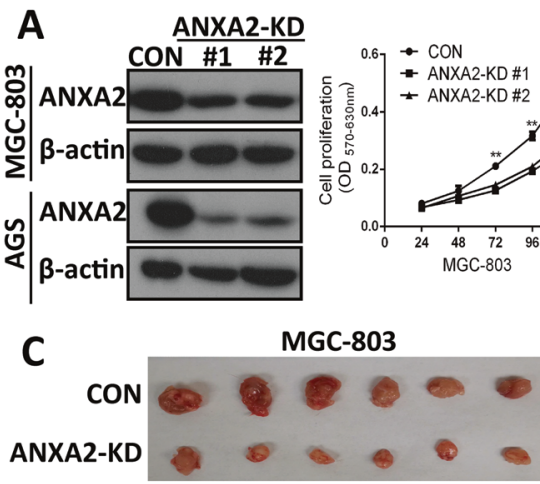

D

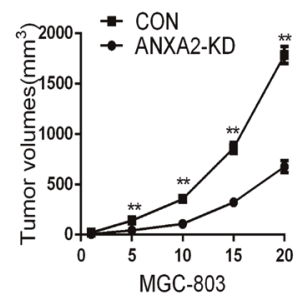

G

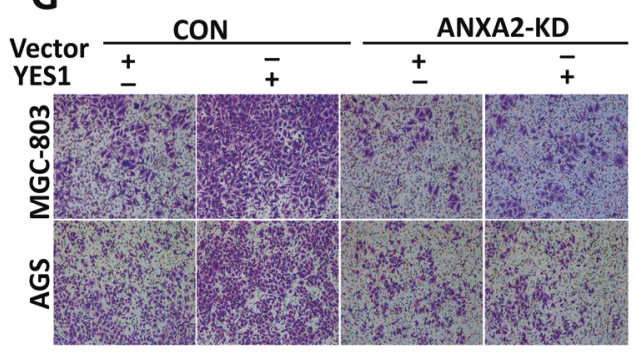

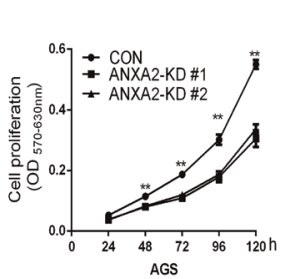
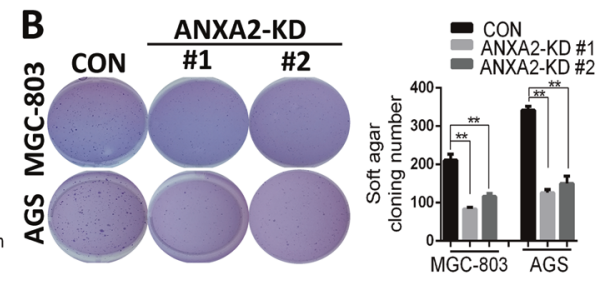
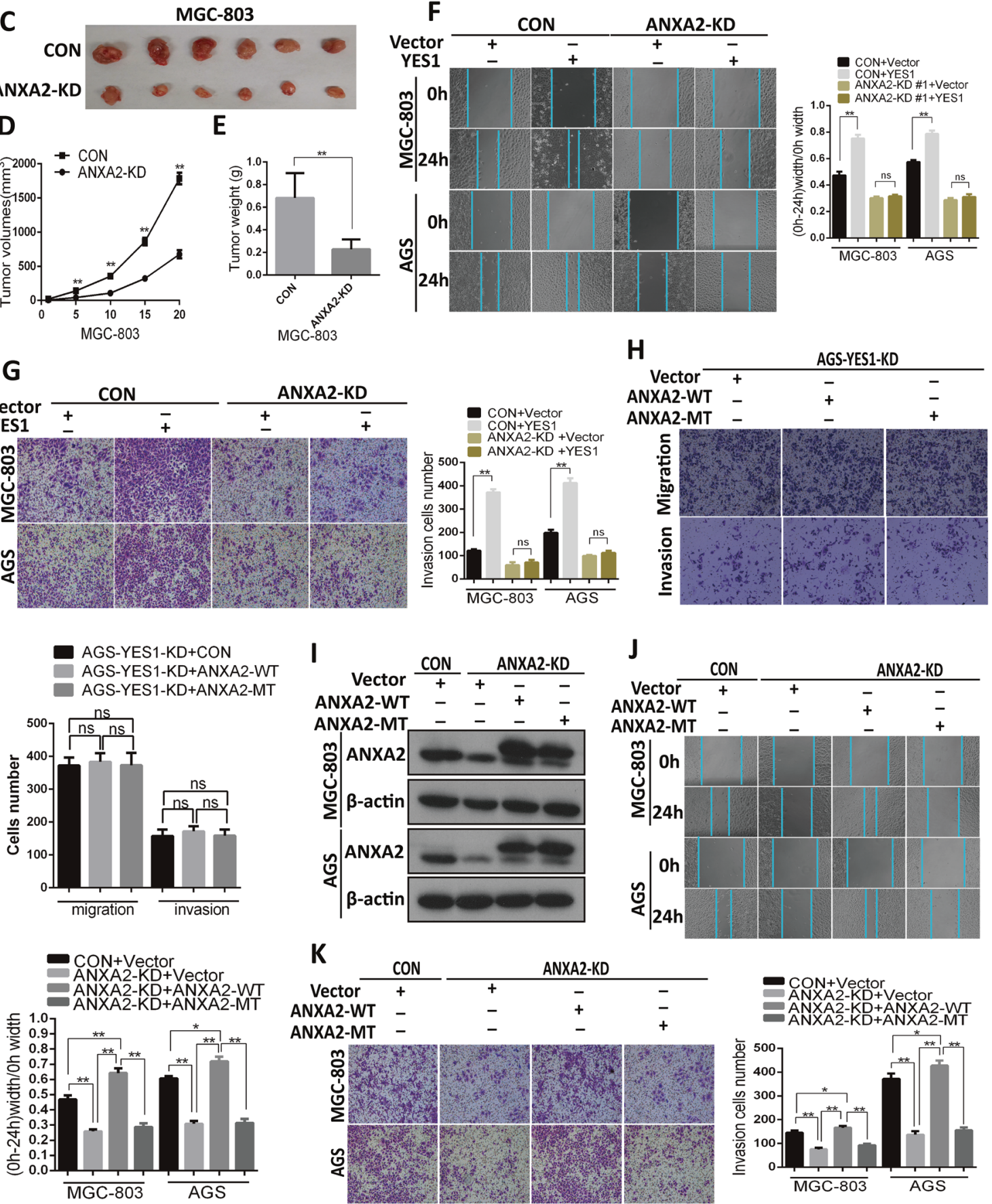
Fig. 5 ANXA2-Tyr24 phosphorylation by YES1 promotes GC cell migration and invasion. A Western blot for the expression of indicated proteins in ANXA2-KD AGS and MGC-803 cells. MTT analysis for cell proliferation rates of control and ANXA2-KD MGC-803 and AGS cells. B Representative images of soft agar colony formation assay for control and ANXA2-KD MGC-803 and AGS cells. C-E ANXA2-KD and control MGC-803 cells were inoculated subcutaneously in NOD-SCID mice, tumor images are shown (C), and tumor size was measured every five days (D). Twenty days later mice were sacrificed and tumor were collected and weighted (E). F Representative images and quantification data of scratch woundhealing assay for control and ANXA2-KD GC cells transfected with control or YES1 expression plasmid at 0 and $24 \mathrm{~h}$ after wound scratch. G Representative images and quantification data of the trans-well migration and invasion assay for control and ANXA2-KD GC cells transfected with control or YES1 expression plasmid. $\mathbf{H}$ Representative images and quantification data of the trans-well migration and invasion assay for AGS-YES1-KD cells transfected with control, WT and MT-ANXA2 expression plasmid respectively. I Western blot for the expression of indicated proteins in control and ANXA2-KD GC cells transfected with control, WT-ANXA2, or MT-ANXA2-Y24F expression plasmid for $48 \mathrm{~h}$. J The representative images and quantification data of scratch wound-healing assay for control and ANXA2-KD GC cells transfected with control, WT-ANXA2 or MT-ANXA2-Y24F expression plasmid at 0 and $24 \mathrm{~h}$ after wound scratch. $\mathbf{K}$ The representative images and quantification data of the trans-well invasion assay control and ANXA2-KD GC cells transfected with control, WT-ANXA2, or MT-ANXA2Y24F expression plasmid. 